\title{
Molecular and Structure-Properties Comparison of an Anionically Synthesized Diblock Copolymer of the PS-b-PI Sequence and Its Hydrogenated or Sulfonated Derivatives
}

\author{
Nikolaos Politakos 1,2 ${ }^{1 D}$, Ioannis Moutsios ${ }^{1}$ D, Gkreti-Maria Manesi ${ }^{1}$ (D), Konstantinos Artopoiadis ${ }^{1}$, \\ Konstantina Tsitoni $^{1}$ (D), Dimitrios Moschovas ${ }^{1,3}$, Alexey A. Piryazev ${ }^{3,4}{ }^{(D}$, Denis S. Kotlyarskiy ${ }^{3,4}$ DD \\ Galder Kortaberria ${ }^{5}$ (D), Dimitri A. Ivanov ${ }^{3,4,6, *(D)}$ and Apostolos Avgeropoulos 1,3,*(D)
}

1 Department of Materials Science Engineering, University Campus-Dourouti, University of Ioannina, 45110 Ioannina, Greece; nikolaos.politakos@ehu.eus (N.P.); imoutsios@uoi.gr (I.M.); gretimanesi@uoi.gr (G.-M.M.); kartopoiades@gmail.com (K.A.); k.tsitoni@uoi.gr (K.T.); dmoschov@uoi.gr (D.M.)

2 POLYMAT and Departamento de Química Aplicada, Facultad de Ciencias Químicas, University of the Basque Country (UPV/EHU), Joxe Mari Korta Zentroa, Tolosa Etorbidea 72, 20018 Donostia-San Sebastián, Spain

3 Faculty of Chemistry, Lomonosov Moscow State University (MSU), GSP-1, 1-3 Leninskiye Gory, 119991 Moscow, Russia; stunnn@gmail.com (A.A.P.); $9920860 @$ gmail.com (D.S.K.)

check for updates

Citation: Politakos, N.; Moutsios, I.; Manesi, G.-M.; Artopoiadis, K.; Tsitoni, K.; Moschovas, D.; Piryazev, A.A.; Kotlyarskiy, D.S.; Kortaberria, G.; Ivanov, D.A.; et al. Molecular and Structure-Properties Comparison of an Anionically Synthesized Diblock Copolymer of the PS- $b$-PI Sequence and Its Hydrogenated or Sulfonated Derivatives. Polymers 2021, 13, 4167. https://doi.org/10.3390/polym 13234167

Academic Editor:

Constantinos Tsitsilianis

Received: 9 November 2021

Accepted: 25 November 2021

Published: 28 November 2021

Publisher's Note: MDPI stays neutral with regard to jurisdictional claims in published maps and institutional affiliations.

Copyright: (c) 2021 by the authors. Licensee MDPI, Basel, Switzerland. This article is an open access article distributed under the terms and conditions of the Creative Commons Attribution (CC BY) license (https:// creativecommons.org/licenses/by/ $4.0 /)$.
4 Institute of Problems of Chemical Physics, Russian Academy of Sciences, Chernogolovka, 142432 Moscow, Russia

5 Materials+Tecnologies' Research Group, Chemistry and Environmental Engineering Department, Faculty of Engineering, Gipuzkoa, University of the Basque Country (UPV/EHU), Plaza Europa 1, 20018 Donostia, Spain; galder.cortaberria@ehu.es

6 Institut de Sciences des Matériaux de Mulhouse-IS2M, CNRS UMR7361, 15 Jean Starcky, 68057 Mulhouse, France

* Correspondence: dimitri.ivanov@uha.fr (D.A.I.); aavger@uoi.gr (A.A.)

Abstract: An approach to obtaining various nanostructures utilizing a well-studied polystyrene$b$-poly(isoprene) or PS- $b$-PI diblock copolymer system through chemical modification reactions is reported. The complete hydrogenation and partial sulfonation to the susceptible carbon double bonds of the PI segment led to the preparation of [polystyrene- $b$-poly(ethylene-alt-propylene)] as well as [polystyrene- $b$-poly(sulfonated isoprene-co-isoprene)], respectively. The hydrogenation of the polyisoprene block results in enhanced segmental immiscibility, whereas the relative sulfonation induces an amphiphilic character in the final modified material. The successful synthesis of the pristine diblock copolymer through anionic polymerization and the relative chemical modification reactions were verified using several molecular and structural characterization techniques. The thin film structure-properties relationship was investigated using atomic force microscopy under various conditions such as different solvents and annealing temperatures. Small-angle X-ray scattering was employed to identify the different observed nanostructures and their evolution upon thermal annealing.

Keywords: anionic polymerization; chemical modification reactions; full hydrogenation; partial sulfonation; molecular characterization; thin films; AFM; self-assembly in bulk; SAXS

\section{Introduction}

A broad class of materials that has attracted significant interest over a wide range of applications in polymer science is diblock copolymers (BCPs). Anionic polymerization has enabled the synthesis of well-defined BCPs exhibiting appealing properties, narrow dispersity and post synthesis modification potential [1-7]. The ability to combine chemically divergent segments leads to various self-assembled nanodomains such as spheres (BCC), hexagonally close-packed cylinders (HCP), double gyroid (DG) and lamellae (LAM) [8-11] 
as well as to uncommon morphologies, rendering the aforementioned systems suitable for nanotechnology $[12,13]$. These hierarchically ordered nanostructures are strongly dependent on the segment-segment interaction parameter $(\chi)$ [14], the volume fraction of each block $\left(\varphi_{\mathrm{A}}\right.$, where $\left.\varphi_{\mathrm{B}}=1-\varphi_{\mathrm{A}}\right)$ and the total degree of polymerization $(N)$. The covalently connected blocks in diblock copolymers microphase separate due to their thermodynamic immiscibility and the $\chi N$ product determines the adopted morphologies above a critical value (equal to 10.5), where the free energy is minimized [9-12,14]. The use of BCPs in advanced technologies is attributed to their tailored physical and chemical properties originating from their well-defined periodic nanostructures [9].

In order to enhance the properties of BCPs, various post-synthetic modification reactions were adopted on susceptible segments by utilizing different techniques such as hydrogenation, epoxidation, hydrosilylation, sulfonation, chlorination, etc. The synthesis of the most chemically modified materials is impossible using conventional polymerization techniques, as already reported in the literature [7,12]. It is of major importance to mention that the degree of polymerization is not affected by the modification reactions; nevertheless, the interaction parameter, $\chi$, between the new segments is significantly altered, leading to differences in the final obtained nanostructures in bulk and/or thin films when compared with the initial pristine copolymer [7].

Concerning the hydrogenation of polydienes, and especially that of the poly(isoprene), quite a few routes for modification reaction have been proposed in the literature involving various catalysts, complexes and chemical reagents. Some of them are related to $\mathrm{Pd} / \mathrm{BaSO}_{4}$ [15], the Ru complex [16,17], the Os complex [18], the Ziegler-Natta type [19], Ni solution [16], $\mathrm{Pt} / \operatorname{Re}$ [20], Wilkinson [21] catalysts, and p-toluenesulfonyl hydrazide [8,9,22-24]. The polystyrene- $b$-poly(isoprene) or PS- $b$-PI diblock copolymer has been extensively studied after hydrogenating the PI segments with one of the aforementioned techniques. It has been proven that non-catalytic hydrogenation using the diimide $\left(\mathrm{N}_{2} \mathrm{H}_{2}\right)$ procedure may induce adverse effects such as the damaging of polymeric chains, the necessity of high temperatures, and PS saturation [25-31]. Despite the drawbacks, studies have concluded that by using reducing agents such as p-toluenesulfonyl hydrazide, $100 \%$ hydrogenation is feasible under specified conditions, leading to materials with improved properties and/or novel morphologies. On the other hand, procedures involving catalytic systems are of paramount importance mainly in industrial applications. Ziegler-type catalysts are commonly encountered in polymer hydrogenation, leading to high conversion and adequate balance between selectivity and reactivity [25-31].

Regarding the sulfonation modification of the PI block, the most common reactions utilize a complex of sulfur trioxide/1,4 dioxane [23,24,32-34] and chlorosulfonyl isocyanate [15]. Sulfur/dioxane complexes are able to act as sulfonation reagents only for PI segments without sulfonating the PS blocks.

Among the most commonly utilized chemical modification techniques is the hydrogenation of polydienes, where the existence of the double bond facilitates the reaction with a number of reagents, inducing desirable physical properties such as thermo-oxidative stability $[14,17,19,35]$ and ultra-violet radiation resistivity [36]. Another method of a postpolymerization chemical modification technique, namely selective block sulfonation, is applied in order to generate materials that present amphiphilic properties in both bulk and thin films providing physical stability to the modified BCPs. It should be mentioned that in the literature such materials have been proposed as micelles, polysoaps, polymeric surfactants, solution modifiers, emulsifiers, wetting agents and foam stabilizers [10,15,32]. Furthermore, polymer electrolyte membranes [37-40] as well as membranes exhibiting transport/permeation [31] properties were reported using the specific materials. Their use as membranes [41,42] has been expanded to polyelectrolyte brushes as antimicrobial surfaces [22], drug delivery and/or controlled-release systems [22,32]. Post-polymerization modifications have gained remarkable interest in industrial applications as well as in academic research, since the final materials present exquisite properties and are not able to be synthesized using conventional polymerization techniques [43-46]. 
To the best of our knowledge, surface studies regarding copolymers containing polydiene segments after chemical modification have not yet been reported in the literature, except for a previous work by Politakos et al. [47] involving only hydrogenated linear triblock copolymers from initial ABA-type SIS and SBS samples (B is poly(polybutadiene)-1,4).

In this study, after synthesizing the diblock copolymer of the PS-b-PI type via anionic polymerization, two different post-polymerization chemical modifications took place in order to molecularly and morphologically characterize the effect of the hydrogenation and the partial sulfonation of the PI block on the BCP behavior. The well-defined, anionically synthesized diblock copolymer (PS- $b$-PI or SI) was transformed into [polystyrene- $b$ poly(ethylene-alt-propylene)] (SEP) after employing the hydrogenation technique, whereas the sulfonation of the PI block resulted in a partially modified amphiphilic material, namely the polystyrene- $b$-poly(sulfonated isoprene-co-isoprene) (SI/sulf). The modification reaction scheme is illustrated in Scheme 1.

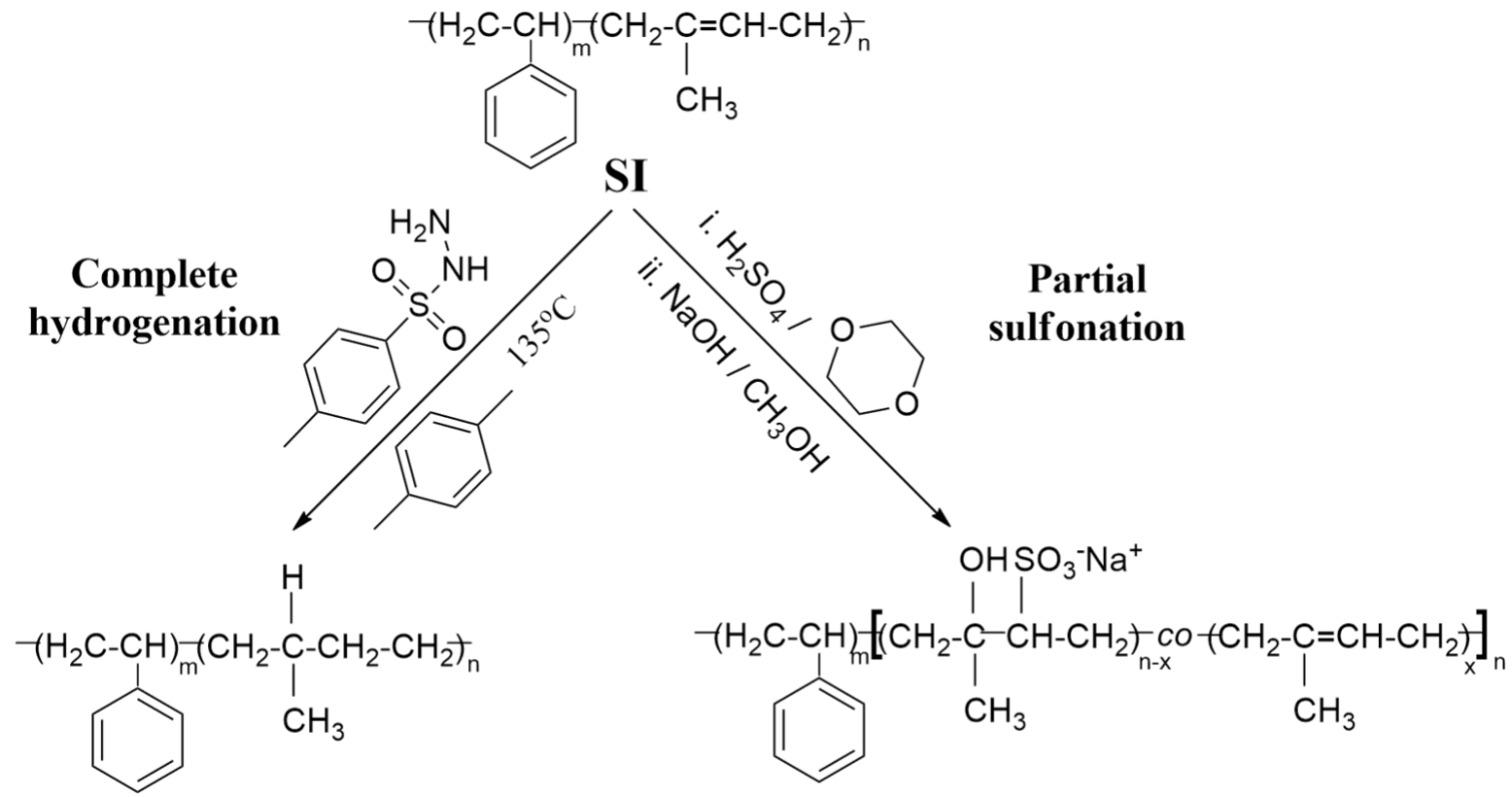

SEP

SI/sulf

Scheme 1. Chemical modification reactions through the complete hydrogenation and partial sulfonation of the initial pristine diblock copolymer (PS- $b$-PI or SI).

The polystyrene block remained intact due to the selective reagent attack towards the double bonds of the PI segments, eventually leading to three different chemical structures capable of adopting various morphologies based on the spin casting solution (dilution of the samples in polar and non-polar solvents: THF, toluene, cyclohexane) and annealing conditions used. Specifically, after the successful verification of the chemical modifications through size exclusion chromatography (SEC), nuclear magnetic resonance (NMR) and infrared spectroscopy (IR), all copolymer sequences were morphologically characterized in terms of atomic force microscopy (AFM) in the thin film state. AFM studies were performed for all the copolymer sequences under various parameters such as casting solvent (toluene, tetrahydrofuran and cyclohexane) and different annealing temperatures (room temperature (R.T.), $80^{\circ} \mathrm{C}, 100{ }^{\circ} \mathrm{C}$ and $120^{\circ} \mathrm{C}$ ). The manipulation of the enthalpic parameters of each sequence holds a significant role on the final adopted morphology, which is strongly affected by the use of selective/non-selective solvents, as well as the enhanced $\chi$ parameter due to the diminished side-groups (hydrogenation) or the existence of heteroatoms (sulfonation) in the PI blocks. Finally, small-angle X-ray scattering (SAXS) was carried out in order to investigate the morphology of the specific copolymer sequences in bulk, further verifying the temperature effect on the adopted structures. 


\section{Materials and Methods}

\subsection{Materials}

The initial diblock copolymer, polystyrene- $b$-polyisoprene (SI), being the precursor for the post-synthetic chemical modification reactions, was synthesized by sequential anionic polymerization under high vacuum techniques. The purification of all reagents involved in the polymerization has already been described in the literature $[7,48]$. All monomers (styrene, isoprene), solvents (benzene, tetrahydrofuran, methanol, 1,4-dioxane, p-xylene, sulfuric acid, cyclohexane, toluene and deuterated chloroform), initiators (secondary-butyl lithium or sec-Buli) and reagents such as p-toluenesulfonyl hydrazide were purchased from Sigma-Aldrich (Sigma-Aldrich Co., St Louis, MO, USA).

The initial SI copolymer was subjected to two different chemical modifications in order to alter, completely or partially, the chemical structure of the PI segment leading either to [polystyrene- $b$-poly(ethylene-alt-propylene)] (SEP) after complete hydrogenation or to polystyrene- $b$-poly(sulfonated isoprene-co-isoprene) (SI/sulf) after partial sulfonation.

The complete hydrogenation of the PI block was achieved using the reducing agent p-toluenesulfonyl hydrazide in p-xylene at $135^{\circ} \mathrm{C}$, as it has already been described in the literature [22]. The exclusive partial sulfonation of the PI segment was realized taking advantage of a sulfur trioxide/1,4-dioxane complex, as already reported elsewhere [33,34].

The analytical synthetic protocol of all diblock copolymer sequences (pristine and chemically modified) is described in the Supporting Information.

\subsection{Methods}

The molecular characterization of the initial copolymer and its derivatives was conducted by size exclusion chromatography using a PerkinElmer (Waltham, MA, USA) chromatograph equipped with a binary pump and a refractive index (RI) detector. The eluent used was THF and separation was carried out with four columns packed with particle gels bearing different nominal pore sizes. The elution rate was $1 \mathrm{~mL} / \mathrm{min}$ at $30{ }^{\circ} \mathrm{C}$. The molecular weights were calculated based on a calibration curve from monodisperse polystyrene standards.

Infrared spectroscopy (FT-IR) was performed with a Nicolet Nexus 670 (Wake Forest, NC, USA) spectrometer equipped with a single horizontal golden gate attenuated total reflectance (ATR) cell. Spectra were recorded by averaging 20 scans between 4000 and $400 \mathrm{~cm}^{-1}$ with a resolution of $2 \mathrm{~cm}^{-1}$ under ambient conditions.

${ }^{1} \mathrm{H}-\mathrm{NMR}$ and ${ }^{13} \mathrm{C}-\mathrm{NMR}$ spectroscopy were used in order to determine the composition along with the microstructure of the PI segments, as well as to verify the successful chemical modifications (hydrogenation and sulfonation). Samples were dissolved in deuterated chloroform $\left(\mathrm{CDCl}_{3}\right)$. The spectra were recorded at room temperature on an Avance Bruker $500 \mathrm{MHz}$ (Rheinstetten, Germany) equipped with a Bruker DSX NMR spectrometer with a $\mathrm{BBO}$ z-gradient probe using a rate of $5000 \mathrm{~Hz}$, a frequency of $500 \mathrm{MHz}$ and a delay of $1 \mathrm{~s}$.

A morphological characterization in order to evaluate the surface morphology of all thin film samples using different parameters (temperature and solvent) was accomplished with a Nanoscope IVa Dimension 3100 AFM (Digital Instruments, Plainview, NY, USA). A tapping mode in air was employed using an integrated silicon tip/cantilever $(125 \mu \mathrm{m}$ in length and with a resonant frequency of ca. $300 \mathrm{kHz}$ ) at a scan rate of $1.0 \mathrm{~Hz}$ and a resonance frequency of $\sim 300 \mathrm{kHz}$. The measurements were performed with 512 scan lines. All samples were dissolved in different solvents (THF, toluene, cyclohexane), preparing $5 \mathrm{wt} \%$ solution concentrations using spin casting onto glass substrates in ambient conditions under specific conditions (2000 rpm for $60 \mathrm{~s}$ ), which led to thicknesses ranging from $50 \mathrm{~nm}$ to $100 \mathrm{~nm}$ (depending on the evaporating solvent). After the complete evaporation of the solvents, the casted samples were annealed at the following temperatures: room temperature, $80^{\circ} \mathrm{C}$, $100{ }^{\circ} \mathrm{C}$ and $120^{\circ} \mathrm{C}$.

For the cleaning procedure of the substrates, a piranha solution was used $\left(\mathrm{H}_{2} \mathrm{O}_{2}\right.$ $30 \%$ and $\mathrm{NH}_{4} \mathrm{OH} 35 \%, 1: 1: 5$ volume fractions of hydrogen peroxide solution, ammonium hydroxide solution, and water, respectively, for $1 \mathrm{~h}$ at $60^{\circ} \mathrm{C}$ ). In addition, the substrates 
were washed with pure ethanol and, prior to use, were placed in an $\mathrm{UV} / \mathrm{O}_{3}$ chamber for approximately $30 \mathrm{~min}$ in order to remove any organic material residue.

The parameters used for the spin coating procedure were as follows: a spinning velocity of $\sim 3000 \mathrm{rpm}$ and a polymer solution concentration equal to $3 \%$ for approximately $30 \mathrm{~s}$.

The thin films were prepared by spin casting onto glass substrates under ambient conditions. In addition, the bulk samples were cast at ambient conditions for at least seven days in order to promote the thermodynamically stable phases.

The structure in the bulk films was studied with small-angle X-ray scattering (SAXS). The 2D X-ray patterns were measured with a Xenocs WAXS/SAXS X-ray (Grenoble, France) system using a Pilatus $300 \mathrm{~K}$ detector and a Genix3D X-ray source with a wavelength of $1.542 \AA$. The calibration, 1D reduction and analysis of the patterns were performed with home-made routines designed in Igor Pro software (WaveMetrics Inc. Portland, OR, USA). The values of the sample-detector distance and reciprocal space vector $\mathbf{s}(|\mathrm{s}|=2 \sin (\theta) / \lambda)$ were calibrated using several orders of the main scattering peak of a silver behenate powder. All bulk samples were prepared using a $5 \mathrm{wt} \%$ solution in THF and/or toluene prior to SAXS experiments.

\section{Results and Discussion}

\subsection{Molecular Characterization}

Size Exclusion Chromatography. The technique was employed in order to molecularly characterize the SI sample as well as the chemically modified materials, regarding their molecular homogeneity, narrow dispersity and the absence of any by-products that would be attributed to side reactions in the final modified BCPs. From SEC results, the total number-average molecular weights were calculated as equal to $56.7 \mathrm{~kg} / \mathrm{mol}$, exhibiting a narrow dispersity index $(\Theta=1.04)$ for the initial BCP; specifically, the PS number average molecular weight was estimated to be $40.6 \mathrm{~kg} / \mathrm{mol}$, whereas it was estimated to be $16.1 \mathrm{~kg} / \mathrm{mol}$ for the PI segment. In Figure 1, all chromatograms, including the PS homopolymer together with the SI, SEP and SI/sulf copolymers, are presented, verifying the absence of by products and the maintenance of the monomodal distributions at the same elution time even though the PI hydrodynamic radius is altered [23,24].

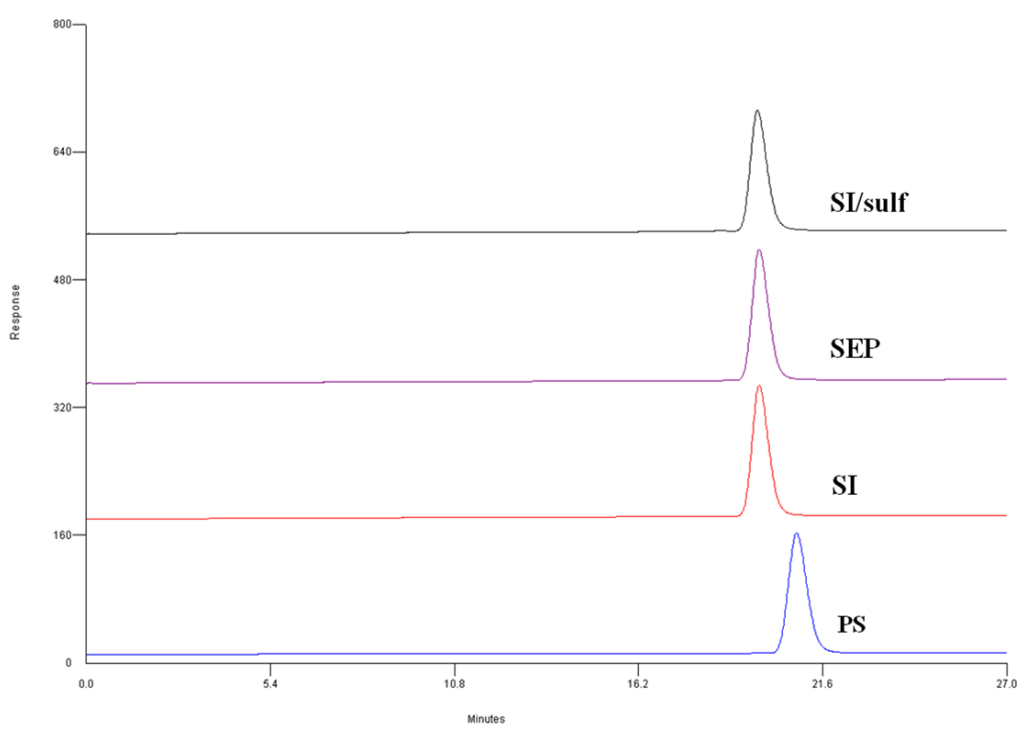

Figure 1. SEC chromatograms of the synthesized materials where the color blue corresponds to the PS homopolymer precursor, red to the SI diblock copolymer, purple to the hydrogenated SEP sample and black to the sulfonated SI/sulf copolymer.

Infrared Spectroscopy. This specific technique was used in order to identify the characteristic chemical groups evident in the SI, the SEP and the SI/sulf copolymers and to assess the successful outcome of the modification reactions. After sulfonation, the double 
bond $(>\mathrm{C}=\mathrm{C}<$ ) of the PI monomeric units were severely diminished, since the yield of the reaction was not $100 \%$. In the case of complete hydrogenation, the carbon double bonds were eliminated. The different microstructures of the PI $\left(-1,4: 839 \mathrm{~cm}^{-1} /-3,4: 890 \mathrm{~cm}^{-1}\right.$ and $\left.-1,2: 910 \mathrm{~cm}^{-1}\right)[17,49,50]$ showcased a similar behavior. Therefore, the band intensities in the modified materials were either decreased (after partial sulfonation) or completely disappeared (after full hydrogentation). Additionally, the attached sulfonyl groups to the PI modified monomeric units resulted in the appearance of new peaks attributed to the hydrophilic character, as indicated by the $-\mathrm{OH}$ groups of the amphiphilic SI/sulf copolymer.

In Figure 2i the FT-IR spectra for all samples are presented and the expected alternations are indicated. In Figure 2ii, a magnified area of the FT-IR spectra is illustrated in order to highlight the differences in the characteristic groups for the initial copolymer and the respective derivatives. Furthermore, in Table S1 (in the Supporting Information), the characteristic peaks of all samples are presented in comparison with the theoretically predicted peaks.
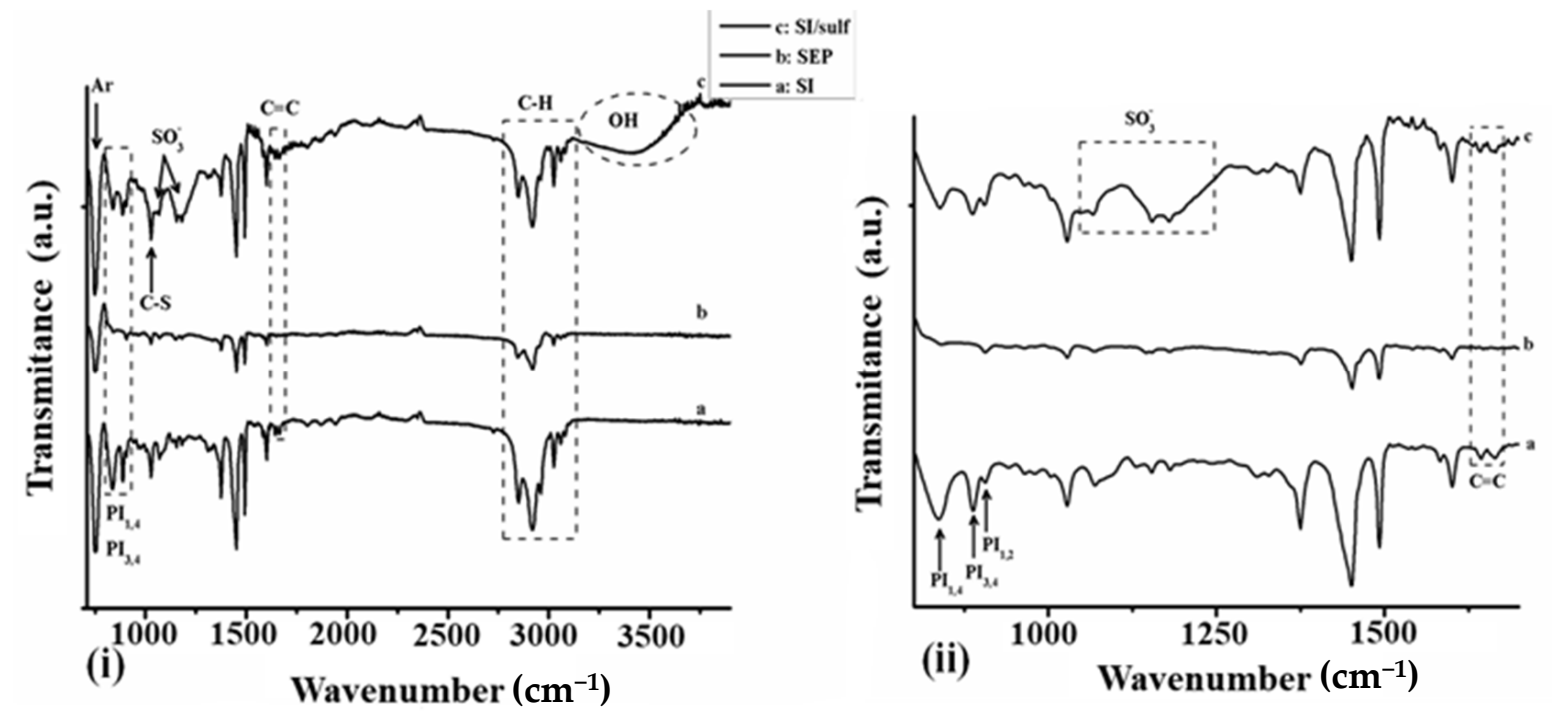

Figure 2. FT-IR spectra of (a) SI, (b) SEP and (c) SI/sulf copolymers indicating the characteristic groups as well as the differences after chemical modification reactions. The spectra in (i) correspond to wavelengths from 750 to $3750 \mathrm{~cm}^{-1}$ and in (ii) to magnified areas from 750 to $1750 \mathrm{~cm}^{-1}$.

Analyzing the data from the FT-IR spectra, important results regarding the chemical modifications can be extracted. The $>\mathrm{C}=\mathrm{C}<$ bond as well as the $>\mathrm{C}-\mathrm{H}$ bond on the aromatic ring can be clearly identified at $1500 \mathrm{~cm}^{-1}, 1600 \mathrm{~cm}^{-1}$ and $760 \mathrm{~cm}^{-1}$, respectively [18], whereas after $3000 \mathrm{~cm}^{-1}$, the C-H vibrations are evident [18]. The characteristic stretching of the double bond of the PI block at $1664 \mathrm{~cm}^{-1}$ [18] as well as the characteristic peaks for the different microstructures $(-1,4,-1,2$ and $-3,4)$ at the regime of $839-910 \mathrm{~cm}^{-1}$ [49] are evident. Furthermore, the presence of fewer peaks in the area of $800-1000 \mathrm{~cm}^{-1}$ after hydrogenation, are observed [19], whereas for the SI/sulf sample, new intense peaks emerged due to the sulfonation. As far as the sulfonated sample is concerned, two different types of peaks attributed to the sulfonyl group $\left(\mathrm{SO}_{3}{ }^{-}\right.$) are evident (symmetric vibrations at $1042 \mathrm{~cm}^{-1}$ and antisymmetric vibrations at $1184 \mathrm{~cm}^{-1}$ ). Finally, the presence of $-\mathrm{OH}$ stretching vibrations at $3500 \mathrm{~cm}^{-1}$ (due to humidity) further confirm the amphiphilic character of the sulfonated material as expected [51].

Proton Nuclear Magnetic Resonance $\left({ }^{1} \mathrm{H}-\mathrm{NMR}\right)$ and Carbon Nuclear Magnetic Resonance $\left({ }^{13} \mathrm{C}-\mathrm{NMR}\right)$ Spectroscopy. Nuclear magnetic resonance spectroscopy was applied in order to determine the composition of each segment as well as the volume fractions, the PI microstructures, and the degree of hydrogenation and sulfonation. The volume fractions were calculated from ${ }^{1} \mathrm{H}-\mathrm{NMR}$ mass fractions, using the following block densities: $\mathrm{d}_{\mathrm{PS}}=1.06 \mathrm{~g} / \mathrm{mL}$ and $\mathrm{d}_{\mathrm{PI}}=0.93 \mathrm{~g} / \mathrm{mL}$. 
The ${ }^{1} \mathrm{H}-\mathrm{NMR}$ spectra of the initial copolymers, as well as the hydrogenated and the sulfonated copolymers, are presented in Figure 3. In Figure 3a, the characteristic chemical shifts at 5.10 parts per million (ppm) are attributed to the one proton of the monomeric unit of the $\mathrm{PI}_{1,4}$ microstructure, whereas those at $4.70 \mathrm{ppm}$ are assigned to the two protons of the monomeric units of the $\mathrm{PI}_{3,4}$ microstructure for the initial diblock copolymer. In Table S2 (in the Supporting Information), the theoretically expected chemical shifts along with the experimentally observed shifts are given.
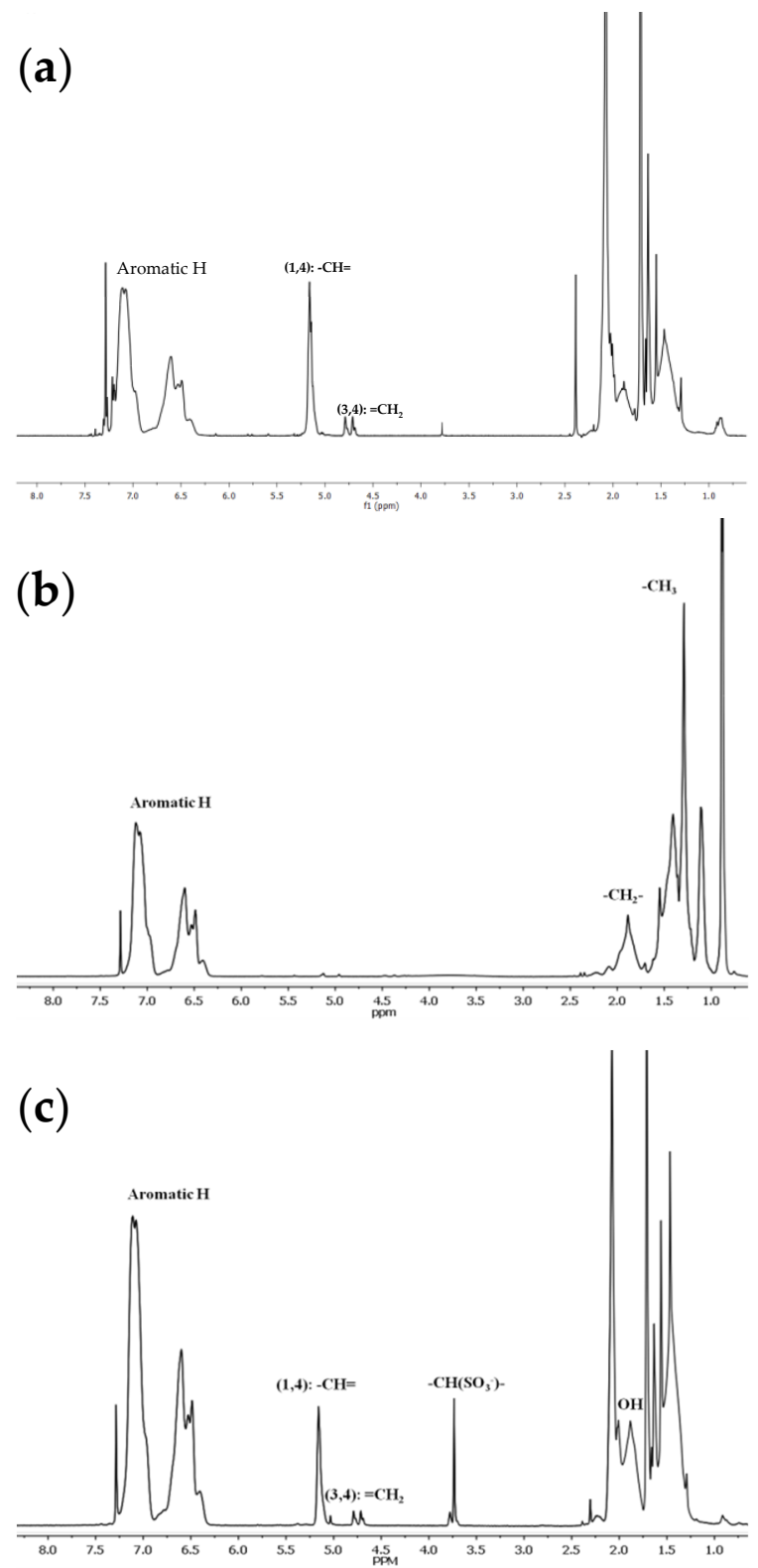

Figure 3. ${ }^{1} \mathrm{H}-\mathrm{NMR}$ spectra of the synthesized materials corresponding to: (a) the initial pristine SI diblock copolymer, (b) the hydrogenated SEP sample indicating an almost $100 \%$ hydrogenation degree and (c) the partially sulfonated SI/sulf copolymer indicating an approximately $43 \%$ sulfonation degree of the PI domains.

Concerning the ${ }^{1} \mathrm{H}-\mathrm{NMR}$ spectrum of the hydrogenated material (Figure $3 b$ ), the major difference lays upon the complete saturation of the carbon double bonds, which is confirmed by the total elimination of the peaks corresponding to the $-\mathrm{H}$ of the double bond for both $-1,4$ and $-3,4$, microstructures, indicating an almost $100 \%$ degree of hydrogenation $[14,17,18,52,53]$. As is evident in Figure $3 b$, the chemical shifts corresponding to the 
PI block are clearly eliminated when compared to the initial spectrum of the copolymer ${ }^{1} \mathrm{H}-\mathrm{NMR}$ (Figure 3a). The intense chemical shifts at the region between 0.50 and $2.00 \mathrm{ppm}$ are attributed to PP (polypropylene) and PE (polyethylene) (methylene and/or methyl units) after the complete hydrogenation of the PI [17,50,52].

The ${ }^{1} \mathrm{H}-\mathrm{NMR}$ spectrum of the sulfonated block copolymer (Figure $3 \mathrm{c}$ ) indicated new chemical shifts due to the alteration of the chemical structure and the presence of the sulfonyl groups $\left(-\mathrm{CH}\left(\mathrm{SO}_{3}{ }^{-}\right)\right.$-) in some of the PI monomeric units. These shifts are located at $3.75 \mathrm{ppm}$, indicating the partially sulfonated PI chains, whereas the presence of hydroxyl groups at $2.00 \mathrm{ppm}$ was also obvious. The incomplete sulfonation reaction was verified by the existence of the characteristic chemical shifts of the PI segment at $\sim 5.00 \mathrm{ppm}$. Taking into consideration the total number-average molecular weight, as well as the mass fractions for both the SI and SI/sulf (5.10 ppm for the PI and $3.75 \mathrm{ppm}$ for the sulfonated PI), a sulfonation degree of approximately $43 \%$ was estimated.

The verification of the characteristic carbon groups attributed to the sulfonyl groups of the modified material was achieved through ${ }^{13} \mathrm{C}-\mathrm{NMR}$ (Figure S1 in the Supporting Information), since the characteristic chemical shifts of the $-\mathrm{C}\left(\mathrm{CH}_{3}\right)(\mathrm{OH})$ - group at $76.0 \mathrm{ppm}$ and $-\mathrm{CH}\left(\mathrm{SO}_{3}{ }^{-}\right)$- at $78.0 \mathrm{ppm}$ strongly indicated the partially successful sulfonation (up to $43 \%)$. It is worth mentioning that the characteristic shifts corresponding to the 1,4-PI microstructure at $125.0 / 135.0 \mathrm{ppm}$ and to the 3,4-PI microstructure at $126.0 / 143.0 \mathrm{ppm}$ are not evident, as can be observed in Figure S1. Furthermore, in Table S3, the theoretically predicted and experimentally observed chemical shifts attributed to the different chemical groups are presented.

\subsection{Morphological Characterization}

Bulk self-assembly morphologies for the diblock copolymer of the SI type have been thoroughly studied and analyzed in the literature [54]. Even though the use of hydrogenated and/or sulfonated materials for membrane applications has been reported in the literature [31,36-39], the surface behavior regarding thin film preparation and the self-assembly of the modified materials has drawn less attention. Different treatment parameters were employed in order to determine the structure-properties relationship of all samples using various organic solvents (toluene, THF and cyclohexane) at multiple annealing temperatures (room temperature, $80^{\circ} \mathrm{C}, 100{ }^{\circ} \mathrm{C}$ and $120^{\circ} \mathrm{C}$ ) utilizing a spin casting method eventually leading to various surface morphologies. Furthermore, the structure evolution under thermal annealing for all copolymers was studied in bulk using SAXS. Both AFM and SAXS results showcased well-ordered structures, indicating the absence of any homopolymer and/or by-product traces.

Different adjustable parameters such as total average molecular weight, structure, composition, conformation, environmental parameters and processing conditions hold a key role in the dissolution of polymeric materials [55] and determine the final adopted morphologies. According to Hansen theory [56], the overall solubility is governed by the following equation:

$$
\delta^{2}=\delta_{\mathrm{d}}^{2}+\delta_{\mathrm{p}}^{2}+\delta_{\mathrm{h}}^{2}
$$

where $\left(\delta_{\mathrm{d}}\right)$ corresponds to dispersion solubility, $\left(\delta_{\mathrm{p}}\right)$ to the dipole solubility and $\left(\delta_{\mathrm{h}}\right)$ to hydrogen bond solubility. Furthermore, these parameters are related to the Flory-Huggins parameter $\chi$, which indicates whether the system will be microphase separated, as can be realized from the equation

$$
\chi_{\mathrm{AB}} \approx\left(\delta_{\mathrm{A}}-\delta_{\mathrm{B}}\right)^{2} \mathrm{~V}_{\text {reff }} / \mathrm{RT}
$$

and among solvents and polymers, as proposed by Equation (3). On the other hand, Equation (4) is suggested by Hansen:

$$
\begin{gathered}
\chi_{\mathrm{sp}}=0.34+\left(\delta_{\mathrm{s}}-\delta_{\mathrm{p}}\right) \mathrm{V}_{\mathrm{s}} / \mathrm{RT} \\
\chi_{\mathrm{sp}}=(\mathrm{aV} / \mathrm{RT})\left[\left(\delta_{\mathrm{ds}}-\delta_{\mathrm{dp}}\right)^{2}+0.25\left(\delta_{\mathrm{ps}}-\delta_{\mathrm{pp}}\right)^{2}+0.25\left(\delta_{\mathrm{hs}}-\delta_{\mathrm{hp}}\right)^{2}\right]
\end{gathered}
$$


The lower the $\chi_{\text {sp }}$ parameter, the better the affinity and, subsequently, the better the mixing, whereas temperature increases result in even smaller values of $\chi_{\mathrm{sp}}$, eventually leading to mixed components $[55,56]$.

For less studied polymers, the parameters $\delta_{d}, \delta_{p}$ and $\delta_{h}$ can be calculated from equations utilizing Hoftyzer and Van Krevelen methods [57], which take into consideration the group contributions $\mathrm{F}_{\mathrm{di}}, \mathrm{F}_{\mathrm{pi}}$ and $\mathrm{E}_{\mathrm{hi}}$ :

$$
\begin{gathered}
\delta_{\mathrm{d}}=\Sigma \mathrm{F}_{\mathrm{di}} / \mathrm{V} \\
\delta_{\mathrm{p}}=\sqrt{ } \Sigma \mathrm{F}_{\mathrm{pi}}{ }^{2} / \mathrm{V} \\
\delta_{\mathrm{h}}=\sqrt{ } \Sigma \mathrm{E}_{\mathrm{di}} / \sqrt{ } \mathrm{V}
\end{gathered}
$$

Additionally, the polymer cohesive energy $\left(\mathrm{E}_{\mathrm{coh}}\right)$ can be directly calculated by a similar method where the solubility parameter can be found using the equation

$$
\Delta=\left(\mathrm{E}_{\mathrm{coh}} / \mathrm{V}\right)^{1 / 2}
$$

Both methods (Hansen and Van Krevelen) were used in order to determine the $\delta$ parameter of the sulfonated PI block. In Table S4 (in the Supporting Information), the results from the aforementioned equations for the $\delta$ parameter are given.

From Table S4 it can be concluded that the calculated $\delta$ parameter that exploits the two different methods for both solvents and polymer blocks is coherent. The deviations found in the SEP and SI/sulf samples are attributed to the calculation method as well as to the strong polar and hydrogen bonding forces, especially for the sulfonated and non-sulfonated PI monomeric units. Taking into consideration correlated studies in the literature [56], similar sulfonated materials exhibit relatively high $\delta_{\mathrm{p}}$ and $\delta_{\mathrm{h}}$ such as chlorosulfonated polyethylene (4.7 and 4.9 $\mathrm{MPa})$, polysulfone (8.3 and 8.3 $\mathrm{MPa}$ ) and polysulphide rubber (17.3 and $16.7 \mathrm{MPa})$.

In order to draw possible conclusions regarding the affinity among the blocks involved in this study, Equation (2) was utilized and through the comparison of $\delta$ parameters of all synthesized segments, it was obvious that the PI/sulf presented less affinity towards the other blocks. In Table 1 , the results regarding the affinity among the abovementioned blocks in different temperatures are presented.

Table 1. Characteristic results for the $\chi_{\mathrm{AB}}$ between all block combinations concerning different chemical structures at different temperatures.

\begin{tabular}{ccccc}
\hline$\chi_{\mathbf{A B}} \rightarrow \mathbf{T}(\mathbf{K})$ & $\mathbf{3 0 0} \mathbf{K}$ & $\mathbf{3 5 3} \mathbf{K}$ & $\mathbf{3 7 3} \mathbf{K}$ & $\mathbf{3 9 3} \mathbf{K}$ \\
\hline$\chi_{\text {PS } / \text { PI }}$ & 0.051 & 0.043 & 0.040 & 0.039 \\
$\chi_{\text {PS } / \text { PEP }}$ & 0.102 & 0.087 & 0.082 & 0.079 \\
$\chi_{\text {PS/PIsulf }}$ & 1.350 & 1.180 & 1.080 & 1.046 \\
$\chi_{\text {PI/PIsulf }}$ & 1.927 & 1.638 & 1.541 & 1.493 \\
\hline
\end{tabular}

All $\chi_{\mathrm{AB}}$ values were calculated from Equation (2), where $\mathrm{V}_{\text {reff }}=100 \mathrm{~cm}^{3} / \mathrm{mol}, \mathrm{R}=8.314 \mathrm{~cm}^{3}$ $\mathrm{MPa} / \mathrm{K} \cdot \mathrm{mol}$ and $\delta$ in $\mathrm{MPa}$, as calculated using the Hansen equation. It should be noted that the values are significantly different (lower) at least for the pristine diblock copolymer based on experimental data, as reported in the literature [54,58-60]. The theoretical calculations are being reported for all different systems for comparison.

It should be noted that due to the partial sulfonation in the case of SI/sulf, three different chemical structures were observed, namely PS, PI and PI/sulf. As a result, the interaction parameter between PI and PI/sulf should not be overlooked. Moreover, the conclusions derived from this study are supported by the literature regarding the $\chi$ parameter which exhibits higher value in the case of PS/PEP $[8,9,61]$.

The affinity of each solvent used, namely THF, toluene and cyclohexane, strongly affects the $\chi_{\mathrm{SP}}$ of each block and taking advantage of Equation (4) along with the $\delta_{\mathrm{d}}$ (solvent/polymer dispersion solubility), $\delta_{\mathrm{p}}$ (solvent/polymer polar solubility) and $\delta_{\mathrm{h}}$ (sol- 
vent/polymer hydrogen bonding solubility), $\chi_{\mathrm{SP}}$ values were estimated and are presented already in the literature by Politakos et al. [47].

More specifically, the PS segments present higher affinity towards THF and slightly less towards toluene and cyclohexane, whereas PI and PEP blocks exhibit higher affinity towards toluene and satisfactory enough towards cyclohexane and THF. PI/sulf blocks display higher affinity in the presence of THF which is attributed to the dispersion forces, the polar and hydrogen bonding as well as to the chemical structure of both polymer and solvent. THF polar character in conjunction with the hydrogen bonding capability render the solvent ideal for the PI/sulf blocks when compared to non-polar solvents such as toluene and cyclohexane, which are preferable for the non-polar polymer blocks (e.g., PI and PEP). As a general remark regarding the THF solvent, apart from the affinity (due to the polarity), another critical parameter is the quick evaporation rate when compared to toluene and cyclohexane, which offers less time for the blocks to self-assemble.

In order to justify the homogeneous surface type topology in the prepared thin films we have calculated from the AFM images the respective roughness (nm), skewness and kurtosis, and the data are illustrated in Table S5 in the Supporting Information. The analysis of the calculated parameters leads to the fact that, according to the solvent used during the spin casting procedure (cyclohexane, THF and toluene) as well as the annealing temperature (R.T., $80^{\circ} \mathrm{C}, 100^{\circ} \mathrm{C}$, and $120^{\circ} \mathrm{C}$ ), the values show a specific trend according to the adopted structure in each case. Further confirmation of the adopted morphologies using toluene as the casting solvent (R.T., $80^{\circ} \mathrm{C}$ ) was achieved by the power spectral density (PSD) calculation results for specific samples, as evident in Figure S3 (Supporting Information).

\subsection{Initial Diblock Copolymer (PS-b-PI or SI)}

Due to the low $\chi$ parameter for the SI system, the use of different solvents at various temperatures led in most cases to significantly less formed structures. Using toluene as a casting solvent at room temperature employing the spin casting method led to predominantly hexagonally close-packed cylinders parallel to the substrate surface (Figure 4a). These are not very well ordered, probably due to the high evaporation speed during the casting process. Additional AFM images for the pristine SI sample for different casting solvents and annealing temperatures are presented in Figure S2a,b (in the Supporting Information), specifically for toluene and cyclohexane at $80^{\circ} \mathrm{C}$ for comparison. The 2D PSD function (Figure S3, left) calculated for the image in Figure 4a shows the presence of only one diffraction peak located at $42.5 \mathrm{~nm}$. After annealing the sample at $80^{\circ} \mathrm{C}$, the structure did not show any significant improvement (cf. Figure S2a), which is reflected in the corresponding 2D PSD function (Figure S3, middle). Indeed, the diffraction peak remains broad and does not show any orientation, whereas its characteristic distance slightly reduces to $40.6 \mathrm{~nm}$. The further characterization of the sample structure has been performed with SAXS. The 2D patterns of the sample cast from THF and the one annealed at $80^{\circ} \mathrm{C}$ (Figure 5 at the top left and top right, respectively) exhibit point-like reflexes, which is indicative of large-size monodomains. The indexation of the patterns to a hexagonal unit cell (cf. Figure 5, bottom left) shows a nice agreement between the experimental and calculated peak positions (Figure S4, left), providing the lattice parameter of 61.1 and $58.6 \mathrm{~nm}$, respectively. Therefore, according to SAXS the lattice shrinks upon annealing by about $4 \%$. This trend is also shown by AFM; however, the uncertainty in the crystallography of the observed plane makes the calculation of the lattice parameter relatively imprecise. Thus, if one assumes that the AFM image captures ten crystallographic planes, the relative error in the determination of the lattice parameter will be about $24 \%$. 


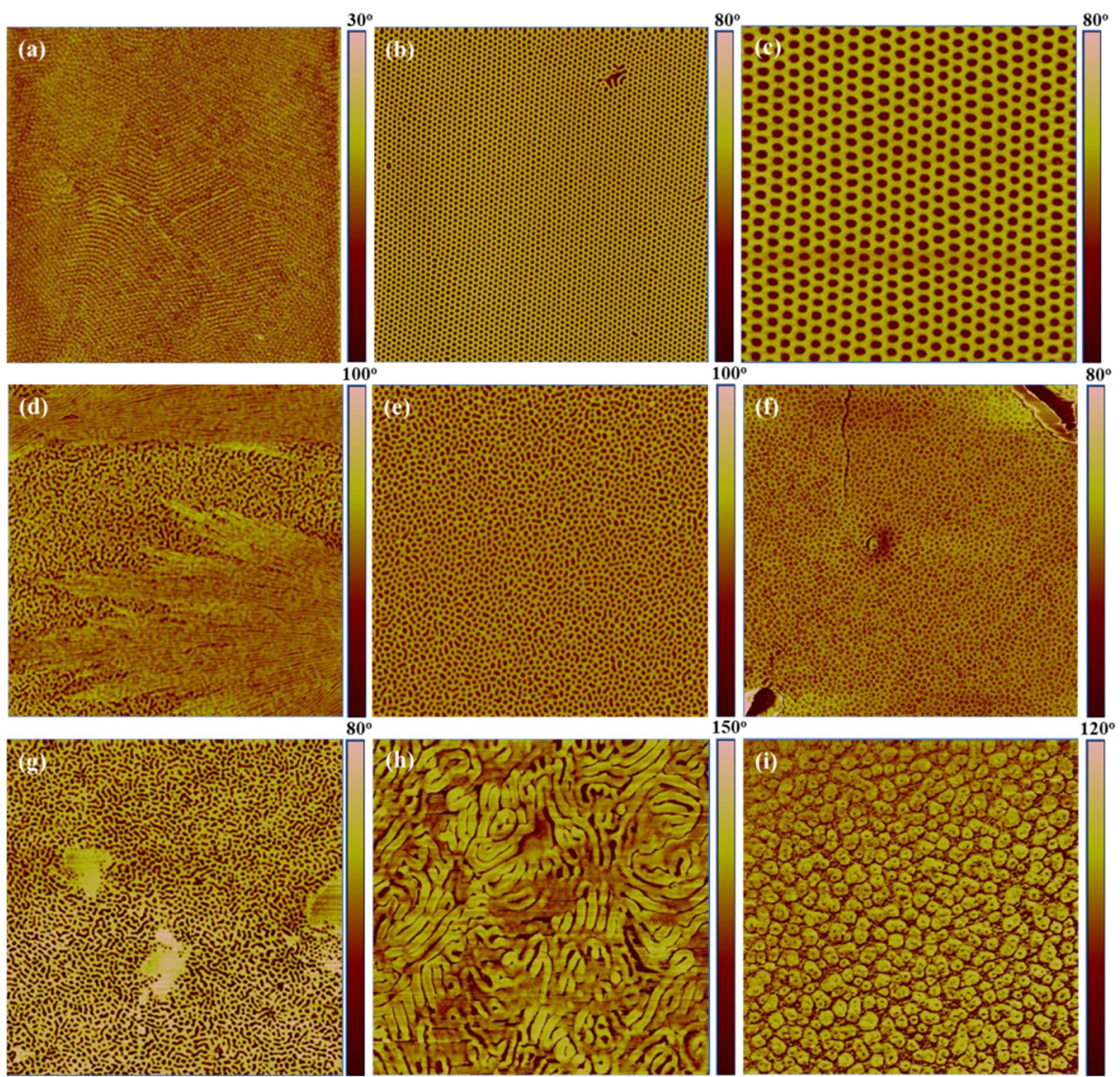

Figure 4. AFM phase images (in all images, the scale is $3 \mu \mathrm{m} \times 3 \mu \mathrm{m}$ except for Figure $4 \mathrm{c}$, where the scale is $1 \mu \mathrm{m} \times 1 \mu \mathrm{m}$ ) corresponding to: (a) the pristine initial diblock copolymer (SI) where hexagonally close-packed cylinders parallel to the substrate surface are observed (toluene/R.T.); (b-g) the 100\% hydrogenated (SEP) material where (b,c) well-ordered hexagonally close-packed cylinders are evident (toluene/R.T.); (d) sponge-like structures in combination with crystallites are obvious (cyclohexane $/ 80^{\circ} \mathrm{C}$ ); (e) hexagonally close-packed cylindrical topology is obtained $\left(\mathrm{THF} / 80^{\circ} \mathrm{C}\right) ;(\mathbf{f}, \mathbf{g})$ disordered structures are observed (THF $/ 100^{\circ} \mathrm{C}$ and $120^{\circ} \mathrm{C}$, respectively); (h,i) the partially sulfonated (SI/sulf) copolymer where (h) horizontal cylinders (cyclohexane/R.T.) and (i) a micellar structure (cyclohexane $/ 80^{\circ} \mathrm{C}$ ) are evident.

\subsection{Hydrogenated Diblock Copolymer (SEP)}

The $100 \%$ hydrogenation of the PI block from the initial pristine diblock resulted in an increase in the $\chi$ parameter value (as calculated theoretically by the Hansen equation, Table 1) if we take into consideration the better ordered structures. Well-ordered hexagonally close-packed cylinders were obtained for the SEP sample when diluted in toluene at room temperature, as evident in Figure $4 b$,c. The PSD function calculated from the AFM image in Figure $4 \mathrm{~b}$ shows a nice hexagonal pattern in the reciprocal space (Figure S3, right), which confirms the highly organized structure visible in the image. The corresponding lattice parameter calculated from the Fourier transform equals $44.2 \mathrm{~nm}$. The SAXS data corresponding to the as-prepared film confirms the hexagonal structure of SEP (cf. Figure 5, bottom right) with the corresponding lattice parameter equal to $51.5 \mathrm{~nm}$. Therefore, the AFM image provides an excellent estimate of the lattice parameter $(51.0 \mathrm{~nm})$, which shows that when the structure is characterized by long-range order and the crystallography of the surface is known, the image can provide a very good estimation of the lattice parameter.

When cyclohexane was used at room temperature, the obtained morphology was different and can be ascribed as a disordered micellar structure probably due to the higher interaction parameter values between the PS and poly(ethylene-alt-propylene) domains. In the case of an annealing temperature equal to $80^{\circ} \mathrm{C}$ and the use of cyclohexane as the 
solvent, the adopted topology was further modified, exhibiting sponge-like structures in combination with crystallites (Figure 4d) due to the existence of the PEP segments (the initiation of crystallization is possible at $80^{\circ} \mathrm{C}$ or below, based on the molecular characteristics).
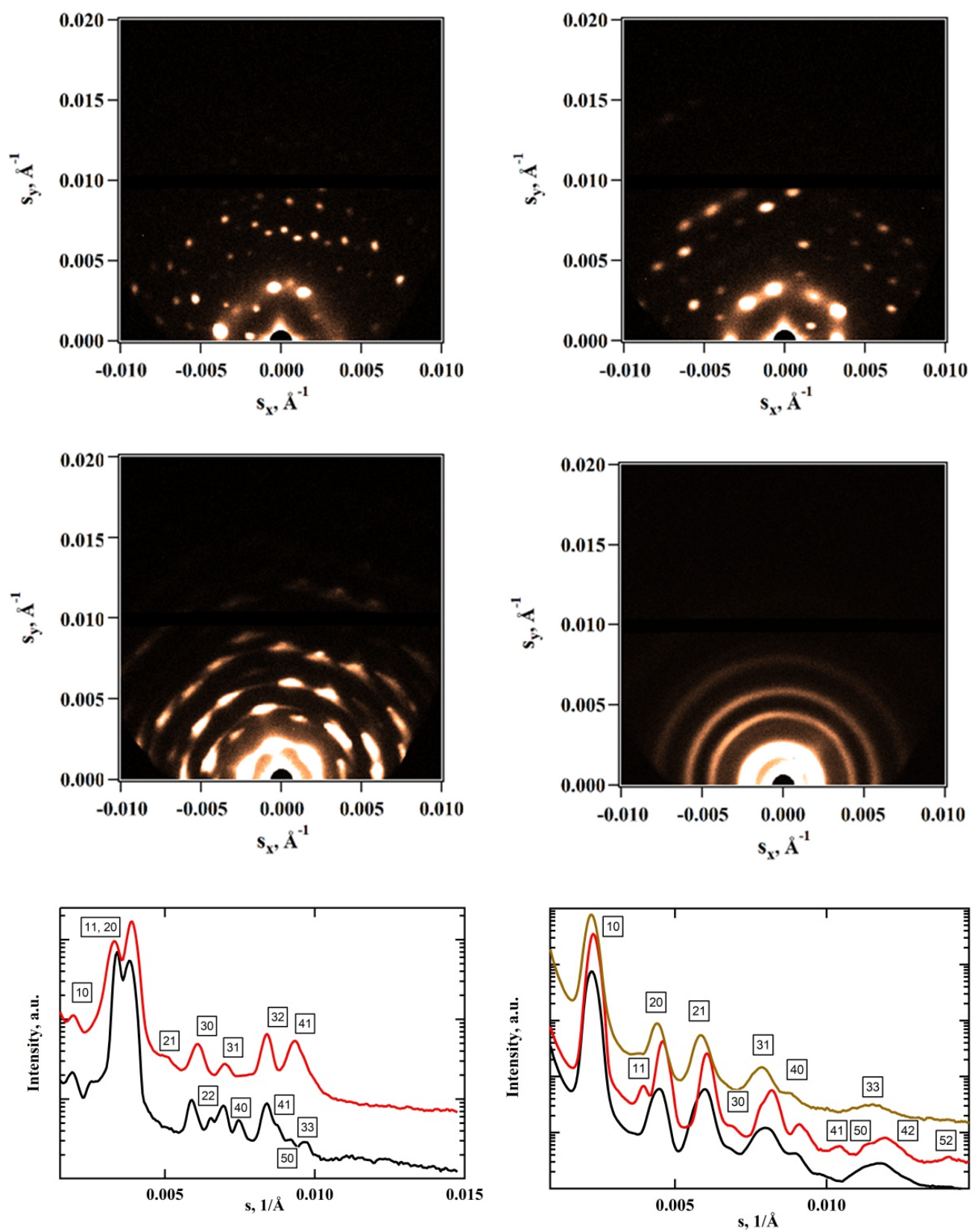

Figure 5. Two-dimensional SAXS patterns of the sample SI cast from THF at R.T. (top left) and subsequently annealed at $80{ }^{\circ} \mathrm{C}$ (top right), as well as the sample SEP cast from THF at R.T. and subsequently annealed at $80^{\circ} \mathrm{C}$ (middle left), and the same sample annealed at $120^{\circ} \mathrm{C}$ (middle right). The 1D-reduced data corresponding to samples SI and SEP described above are given in the bottom left and bottom right panels, respectively. In the bottom graphs, the as-prepared samples are shown in black, the ones annealed at $80^{\circ} \mathrm{C}$ in red and at $120{ }^{\circ} \mathrm{C}$ in brown. The $h k$ indices of the hexagonal lattice are indicated in $1 \mathrm{D}$ curves.

Similarly, by altering the solvent and annealing temperature (THF, $80^{\circ} \mathrm{C}$ ), a hexagonally close-packed cylindrical topology was obtained as depicted in Figure 4e, which is becoming a disordered structure as the annealing temperature increases to $100{ }^{\circ} \mathrm{C}$ (Figure $4 \mathrm{f}$ ) and $120^{\circ} \mathrm{C}$ (Figure $4 \mathrm{~g}$ ) as expected, since the chi parameter values decreased, as evident in Table 1. The SAXS data nicely corroborate this picture. Indeed, the 2D SAXS 
pattern of the SEP sample (THF, $80^{\circ} \mathrm{C}$ ) shows hexagonal packing with a relatively large size of monodomains (Figure 5, middle left), which is evident from the point-like appearance of the peaks. By contrast, upon annealing at $120^{\circ} \mathrm{C}$, the pattern significantly modifies (Figure 5, middle right). Indeed, now the point-like reflexes are absent and replaced by almost uniform rings, which testifies that the monodomain size is drastically reduced. Interestingly, the change in the sample structure can also be monitored from the lattice parameter $a$. The annealing of the sample at $80^{\circ} \mathrm{C}$ brings about a relatively small decrease in $a$ from 51.1 to $50.9 \mathrm{~nm}$, whereas the annealing at $120^{\circ} \mathrm{C}$ causes a more noticeable increase in $a$ to $52.5 \mathrm{~nm}$, which is in line with the sample disordering.

\subsection{Partially Sulfonated Diblock Copolymer (SI/Sulf)}

The partial sulfonation of the initial PI chains with a yield of $43 \%$ resulted in the calculation of not just one Flory-Huggins interaction parameter but two: $\chi_{\mathrm{PS} / \text { PIsulf }}$ and $\chi_{\mathrm{PI} / \text { PIsulf }}$. The latter parameter is the one between non-sulfonated and sulfonated monomeric units in the same PI macromolecules, possibly rendering the specific modified final copolymer less susceptible to dissolution in non-polar solvents. The partially sulfonated PI blocks induced the possible formation of horizontal cylinders (Figure 4h) when cast from cyclohexane at room temperature and were further altered to a possible micellar structure when the sample was annealed at $80^{\circ} \mathrm{C}$ (Figure $4 \mathrm{i}$ ) under the same solvent casting conditions. A similar morphology was observed when using toluene as the casting solvent at temperatures ranging from $80^{\circ} \mathrm{C}$ to $120^{\circ} \mathrm{C}$, as evident in Figure S2c,d (in the Supporting Information).

\section{Conclusions}

We report the synthesis of the polystyrene-b-poly(isoprene) diblock copolymer through anionic polymerization and the subsequent chemical modifications towards the formation of either the polystyrene- $b$-poly[(ethylene)-alt-(propylene)] copolymer or polystyrene- $b$ poly(sulfonated isoprene-co-isoprene). The chemical modification of SI block copolymer was achieved i) through almost $100 \%$ hydrogenation of the PI block in order to obtain a SEP copolymer and ii) through the sulfonation reaction of the PI obtaining a partially sulfonated PI block ( $43 \%$ yield).

All copolymers were molecularly characterized through various techniques in order to verify the successful synthesis and post-polymerization modifications. The chemically modified copolymers were characterized via SEC in order to justify the absence of any undesired side reactions. For the verification of the synthesized SEP and SI/sulf samples, FT-IR, ${ }^{1} \mathrm{H}-\mathrm{NMR}$ and ${ }^{13} \mathrm{C}-\mathrm{NMR}$ techniques were used. A fully hydrogenated material was obtained since the characteristic chemical shifts attributed to the $\mathrm{PI}_{1,4}$ and $\mathrm{PI}_{3,4}$ were completely eliminated while the degree of sulfonation was calculated at approximately $43 \%$ through ${ }^{1} \mathrm{H}-\mathrm{NMR}$. This led to a block copolymer containing PS and coexistent PI sulfonated and non-sulfonated monomeric units.

The structural characterization on the thin film self-assembly of both the copolymer precursor and the final modified materials is reported for the first time to the best of our knowledge. By adopting the spin casting method under specific conditions and varying significant parameters such as solvent (toluene, THF, cyclohexane) and annealing temperature (RT, $80^{\circ} \mathrm{C}, 100^{\circ} \mathrm{C}$ and $120^{\circ} \mathrm{C}$ ) different topologies were justified when studied with atomic force microscopy. It is evident that the pristine copolymer had less well-ordered structures probably due to the fast evaporation rate of the solvents used during the spin casting and the fact that the samples were only annealed for short periods. The highest repulsion among PS and PEP chains led to the formation of long-range morphologies using different solvents and annealing temperatures. For the SI/sulf system, morphologies ranging from disordered to spherical micelles, and even to cylindrical structures, were observed deriving from the process treatment along with the amphiphilic character of the specific material.

The results obtained from AFM were further supported by small-angle X-ray scattering experiments, as could be clearly observed on the $2 \mathrm{D}$ power spectral density data. The 
different adopted nanostructures in bulk were determined using SAXS and the effect of thermal annealing on the obtained morphologies as well as on $d$-spacing were justified.

Supplementary Materials: The following are available online at https://www.mdpi.com/article/ 10.3390/polym13234167/s1, Table S1: Characteristic FT-IR peak wavenumbers for SI, SEP and SI/sulf block copolymers, Table S2: Characteristic chemical groups together with the corresponding theoretical and experimental chemical shifts for the SI, SEP and SI/sulf block copolymers, Figure S1: ${ }^{13} \mathrm{C}$-NMR spectrum for the sulfonated sample SI/sulf where the characteristic chemical shifts justify the successful partial sulfonation procedure, Table S3: Characteristic chemical groups together with the corresponding theoretical and experimental chemical shifts for the SI/sulf block copolymer, Table S4: Characteristic solubility parameters and volume values for each solvent and polymer segment that have been used in order to extract Hansen and Van Krevelen solubility parameters, Table S5: The roughness (nm), skewness and kurtosis as calculated from the AFM images for the initial SI sample, the hydrogenated (PEP) and the sulfonated (SI/sulf) copolymers using cyclohexane, tetrahydrofuran and toluene as casting solvents at different annealing temperatures $\left(\mathrm{RT}, 80^{\circ} \mathrm{C}, 100^{\circ} \mathrm{C}\right.$ and $120^{\circ} \mathrm{C}$ ), Figure S2: AFM phase images $(3 \mu \mathrm{m} \times 3 \mu \mathrm{m}$ except) corresponding to: the pristine initial diblock copolymer (SI) in (a) toluene $/ 80^{\circ} \mathrm{C}$, (b) cyclohexane $/ 80^{\circ} \mathrm{C}$ and to the partially sulfonated (SI/sulf) copolymer (c,d) where possible micellar structures are illustrated in toluene $/ 100{ }^{\circ} \mathrm{C}$ (c) and toluene $/ 120^{\circ} \mathrm{C}(\mathrm{d})$, respectively, Figure S3: 2D Power spectral density functions corresponding to AFM images (Figure 4a,b and Figure S2a) of the pristine initial diblock copolymer (SI) cast from toluene at R.T. (left), the same sample after annealing at $80{ }^{\circ} \mathrm{C}$ (middle) and the $100 \%$ hydrogenated (SEP) material in the as-prepared state (right). The dashed green circles are tranced through the fundamental diffraction peak, Figure S4: Comparison of the experimental and calculated d-spacings for samples SI cast from toluene at R.T. and upon annealing at $80^{\circ} \mathrm{C}$ (left) and the SEP material cast from THF at R.T. and upon annealing at $80^{\circ} \mathrm{C}$ and $120^{\circ} \mathrm{C}$ (right). The solid lines correspond to equation $y=x$. (See main text for more details).

Author Contributions: Conceptualization, A.A.; methodology, N.P., G.K. and A.A.; validation, G.K., D.A.I. and A.A.; formal analysis, N.P., I.M., G.-M.M. and A.A.; data curation, N.P., I.M., G.-M.M., K.A., K.T., D.M., A.A.P., D.S.K. and A.A.; writing—original draft preparation, N.P., I.M., G.-M.M., D.A.I. and A.A.; writing—review and editing, G.K., D.A.I. and A.A.; supervision, G.K., D.A.I. and A.A. All authors have read and agreed to the published version of the manuscript.

Funding: D.M., A.A.P., D.S.K., D.A.I. and A.A. acknowledge financial support from the Ministry of Science and Higher Education of the Russian Federation within State Contract 075-15-2019-1889. The research work was partially supported by the Hellenic Foundation for Research and Innovation (H.F.R.I.), under the H.F.R.I. PhD fellowship grant (fellowship no. 1650) for I.M. The research work was also supported by the Hellenic Foundation for Research and Innovation (H.F.R.I.) under the "First Call for H.F.R.I. Research Projects to Support Faculty Members and Researchers and the Procurement of High-Cost Research Equipment Grant" (Project Number: 3970, acronym: NANOPOLYBRUSH) for K.A., D.M. and A.A.

Institutional Review Board Statement: Not applicable.

Informed Consent Statement: Not applicable.

Data Availability Statement: The data presented in this study are available upon request from the corresponding authors.

Acknowledgments: The authors thank Dmitry Vashurkin and Evgeniia Nikitina for their help in sample preparation for SAXS characterization.

Conflicts of Interest: The authors declare no conflict of interest.

\section{References}

1. Polymeropoulos, G.; Zapsas, G.; Ntetsikas, K.; Bilalis, P.; Gnanou, Y.; Hadjichristidis, N. 50th Anniversary Perspective: Polymers with Complex Architectures. Macromolecules 2017, 50, 1253-1290. [CrossRef]

2. Leibler, L. Theory of Microphase Separation in Block Copolymers. Macromolecules 1980, 13, 1602-1617. [CrossRef]

3. Lohse, D.J.; Hadjichristidis, N. Microphase separation in block copolymers. Curr. Opin. Colloid Interface Sci. 1997, 2, 171-176. [CrossRef] 
4. Romulus, J.; Henssler, J.T.; Weck, M. Postpolymerization Modification of Block Copolymers. Macromolecules 2014, 47, 5437-5449. [CrossRef]

5. Politakos, N.; Kortaberria, G.; Zalakain, I.; Mondragon, I.; Avgeropoulos, A. Enhancing the hydrophobic properties of various commercial polymers through mixtures and coatings with a fluorinated diblock copolymer in low concentrations. Eur. Polym. J. 2013, 49, 1841-1851. [CrossRef]

6. Politakos, N.; Kortaberria, G.; Zalakain, I.; Avgeropoulos, A.; Mondragon, I. Modified diblock copolymer bearing fluoro groups and evaluation of its hydrophobic properties. Macromol. Symp. 2012, 321-322, 53-58. [CrossRef]

7. Politakos, N.; Weinman, C.J.; Paik, M.Y.; Sundaram, H.S.; Ober, C.K.; Avgeropoulos, A. Synthesis, molecular, and morphological characterization of initial and modified diblock copolymers with organic acid chloride derivatives. J. Polym. Sci. Part A Polym. Chem. 2011, 49, 4292-4305. [CrossRef]

8. Kimishima, K.; Jinnai, H.; Hashimoto, T. Control of Self-Assembled Structures in Binary Mixtures of A-B Diblock Copolymer and A-C Diblock Copolymer by Changing the Interaction between B and C Block Chains. Macromolecules 1999, 32, $2585-2596$. [CrossRef]

9. Tureau, M.S.; Epps, T.H. Effect of partial hydrogenation on the phase behavior of poly(isoprene-b-styrene-b-methyl methacrylate) triblock copolymers. Macromolecules 2012, 45, 8347-8355. [CrossRef]

10. Hillmyer, M.A.; Bates, F.S. Synthesis and characterization of model polyalkane-poly(ethylene oxide) block copolymers. Macromolecules 1996, 29, 6994-7002. [CrossRef]

11. Laurer, J.H.; Khan, S.A.; Spontak, R.J.; Satkowski, M.M.; Grothaus, J.T.; Smith, S.D.; Lin, J.S. Morphology and rheology of SIS and SEPS triblock copolymers in the presence of a midblock-selective solvent. Langmuir 1999, 15, 7947-7955. [CrossRef]

12. Hu, H.; Gopinadhan, M.; Osuji, C.O. Directed self-Assembly of block copolymers: A tutorial review of strategies for enabling nanotechnology with soft matter. Soft Matter 2014, 10, 3867-3889. [CrossRef]

13. Park, C.; Yoon, J.; Thomas, E.L. Enabling nanotechnology with self assembled block copolymer patterns. Polymer 2003, 44, 6725-6760. [CrossRef]

14. Davidock, D.A.; Hillmyer, M.A.; Lodge, T.P. Mapping large regions of diblock copolymer phase space by selective chemical modification. Macromolecules 2004, 37, 397-407. [CrossRef]

15. Allgaier, J.; Poppe, A.; Willner, L.; Richter, D. Synthesis and Characterization of Poly[1,4-isoprene- $b$-(ethylene oxide)] and Poly[ethylene-co-propylene- $b$-(ethylene oxide)] Block Copolymers. Macromolecules 1997, 30, 1582-1586. [CrossRef]

16. Mani, S.; Weiss, R.A.; Hahn, S.F.; Williams, C.E.; Cantino, M.E.; Khairallah, L.H. Microstructure of block copolymers of polystyrene and poly(ethylene-alt-propylene). Polymer 1998, 39, 2023-2033. [CrossRef]

17. Charmondusit, K.; Prasassarakich, P.; Mcmanus, N.T.; Rempel, G.L. Hydrogenation of cis-1,4-Poly(isoprene) Catalyzed by $\mathrm{OsHCl}(\mathrm{CO})\left(\mathrm{O}_{2}\right)\left(\mathrm{PCy}_{3}\right)_{2}$. J. Appl. Polym. Sci. 2002, 89, 142-152. [CrossRef]

18. Kongparakul, S.; Prasassarakich, P.; Rempel, G.L. Catalytic hydrogenation of styrene-g-natural rubber (ST-g-NR) in the presence of $\mathrm{OsHCl}(\mathrm{CO})\left(\mathrm{O}_{2}\right)\left(\mathrm{PCy}_{3}\right)_{2}$. Eur. Polym. J. 2009, 45, 2358-2373. [CrossRef]

19. Barrios, V.A.E.; Nájera, R.H.; Petit, A.; Pla, F. Selective hydrogenation of butadiene-styrene copolymers using a Ziegler-Natta type catalyst 1. Kinetic study. Eur. Polym. J. 2000, 36, 1817-1834. [CrossRef]

20. Alfonzo, C.G.; Fleury, G.; Chaffin, K.A.; Bates, F.S. Synthesis and characterization of elastomeric heptablock terpolymers structured by crystallization. Macromolecules 2010, 43, 5295-5305. [CrossRef]

21. Schmalz, H.; Müller, A.J.; Abetz, V. Crystallization in ABC triblock copolymers with two different crystalline end blocks: Influence of confinement on self-nucleation behavior. Macromol. Chem. Phys. 2003, 204, 111-124. [CrossRef]

22. Kaewsaiha, P.; Matsumoto, K.; Matsuoka, H. Synthesis and nanostructure of strong polyelectrolyte brushes in amphiphilic diblock copolymer monolayers on a water surface. Langmuir 2004, 20, 6754-6761. [CrossRef]

23. Tamada, Y.; Murata, M.; Makino, K.; Yoshida, Y.; Yoshida, T.; Hayashi, T. Anticoagulant effects of sulphonated polpisoprenes. Biomaterials 1998, 19, 745-750. [CrossRef]

24. Tamada, Y.; Murata, M.; Hayashi, T.; Goto, K. Anticoagulant mechanism of sulfonated polyisoprenes. Biomaterials 2002, 23, 1375-1382. [CrossRef]

25. Yakubchik, A.I.; Tichomirov, B.I.; Sulimov, V.S. Hydrogenation of Natural and Synthetic cis-1,4-Polyisoprene. Rubber Chem. Technol. 1962, 35, 1063-1065. [CrossRef]

26. Alley, W.M.; Hamdemir, I.K.; Johnson, K.A.; Finke, R.G. Ziegler-type hydrogenation catalysts made from group 8-10 transition metal precatalysts and AlR3 cocatalysts: A critical review of the literature. J. Mol. Catal. A Chem. 2010, 315, 1-27. [CrossRef]

27. Von Tiedemann, P.; Yan, J.; Barent, R.D.; Spontak, R.J.; Floudas, G.; Frey, H.; Register, R.A. Tapered Multiblock Star Copolymers: Synthesis, Selective Hydrogenation, and Properties. Macromolecules 2020, 53, 4422-4434. [CrossRef]

28. Samran, J.; Phinyocheep, P.; Daniel, P.; Kittipoom, S. Hydrogenation of unsaturated rubbers using diimide as a reducing agent. J. Appl. Polym. Sci. 2005, 95, 16-27. [CrossRef]

29. Ricci, G.; Boccia, A.C.; Leone, G.; Pierro, I.; Zanchin, G.; Scoti, M.; Auriemma, F.; De Rosa, C. Isotactic and syndiotactic alternating ethylene/propylene copolymers obtained through non-catalytic hydrogenation of highly stereoregular cis-1,4 poly(1,3-diene)s. Molecules 2017, 22, 755. [CrossRef] [PubMed]

30. Hahn, S.F. An improved method for the diimide hydrogenation of butadiene and isoprene containing polymers. J. Polym. Sci. Part A Polym. Chem. 1992, 30,397-408. [CrossRef] 
31. Gacal, B.N.; Filiz, V.; Shishatskiy, S.; Rangou, S.; Neumann, S.; Abetz, V. Modification of polyisoprene-block-poly(vinyl trimethylsilane) block copolymers via hydrosilylation and hydrogenation, and their gas transport properties. J. Polym. Sci. Part B Polym. Phys. 2013, 51, 1252-1261. [CrossRef]

32. Kaditi, E.; Mountrichas, G.; Pispas, S. Amphiphilic block copolymers by a combination of anionic polymerization and selective post-polymerization functionalization. Eur. Polym. J. 2011, 47, 415-434. [CrossRef]

33. Szczubiałka, K.; Ishikawa, K.; Morishima, Y. Micelle Formation of Diblock Copolymers of Styrene and Sulfonated Isoprene in Aqueous Solution. Langmuir 1999, 15, 454-462. [CrossRef]

34. Szczubiałka, K.; Ishikawa, K.; Morishima, Y. Associating behavior of sulfonated polyisoprene block copolymers with short polystyrene blocks at both chain ends. Langmuir 2000, 16, 2083-2092. [CrossRef]

35. Burns, A.B.; Register, R.A. Strategies for the Synthesis of Well-Defined Star Polymers by Anionic Polymerization with Chlorosilane Coupling and Preservation of the Star Architecture during Catalytic Hydrogenation. Macromolecules 2016, 49, 2063-2070. [CrossRef]

36. Tsai, B.-H.; Lin, T.-A.; Cheng, C.-H.; Lin, J.-C. Studies of the Sulfonated Hydrogenated Styrene-Isoprene-Styrene Block Copolymer and Its Surface Properties, Cytotoxicity, and Platelet-Contacting Characteristics. Polymers 2021, 13, 235. [CrossRef]

37. Yeo, J.; Kim, S.Y.; Kim, S.; Ryu, D.Y.; Kim, T.H.; Park, M.J. Mechanically and structurally robust sulfonated block copolymer membranes for water purification applications. Nanotechnology 2012, 23, 245703. [CrossRef] [PubMed]

38. Isaacs Sodeye, A.I.; Huang, T.; Gido, S.P.; Mays, J.W. Polymer electrolyte membranes from fluorinated polyisoprene-blocksulfonated polystyrene: Membrane structure and transport properties. Polymer 2011, 52, 1963-1970. [CrossRef]

39. Isaacs Sodeye, A.I.; Huang, T.; Gido, S.P.; Mays, J.W. Polymer electrolyte membranes from fluorinated polyisoprene-blocksulfonated polystyrene: Structural evolution with hydration and heating. Polymer 2011, 52, 3201-3208. [CrossRef]

40. Isaacs Sodeye, A.I.; Huang, T.; Gido, S.P.; Mays, J.W. Polymer electrolyte membranes from fluorinated polyisoprene-blocksulfonated polystyrene: Microdomain orientation by external field. Polymer 2011, 52, 5393-5396. [CrossRef]

41. Van Der Velden, P.M.; Smolders, C.A. New cation-exchange membranes for hyperfiltration processes. J. Appl. Polym. Sci. 1977, 21, 1445-1457. [CrossRef]

42. Jonquières, A.; Clément, R.; Lochon, P. Permeability of block copolymers to vapors and liquids. Prog. Polym. Sci. 2002, 27, 1803-1877. [CrossRef]

43. Liu, K.; Zhang, F.; Sun, M.; Xie, F.; Ying, S.; Yang, Z.; Zhou, C.; Xia, J.; Li, A. Thermally Stable and Well-Defined PentadieneDerived Copolymers Prepared by Anionic Alternating Copolymerization and Subsequent Controlled Postmodification. Macromol. Chem. Phys. 2020, 221, 1-9. [CrossRef]

44. Ashraf, A.R.; Ryan, J.J.; Satkowski, M.M.; Smith, S.D.; Spontak, R.J. Effect of Systematic Hydrogenation on the Phase Behavior and Nanostructural Dimensions of Block Copolymers. ACS Appl. Mater. Interfaces 2018, 10, 3186-3190. [CrossRef] [PubMed]

45. Taksapattanakul, K.; Tulyapitak, T.; Phinyocheep, P.; Ruamcharoen, P.; Ruamcharoen, J.; Lagarde, F.; Daniel, P. The effect of percent hydrogenation and vulcanization system on ozone stability of hydrogenated natural rubber vulcanizates using Raman spectroscopy. Polym. Degrad. Stab. 2017, 141, 58-68. [CrossRef]

46. Shiraki, Y.; Yokoyama, H. Novel hydrophobic and oleophobic surfaces using polyurethane with hydrogenated polyisoprene soft segment. Mater. Today Commun. 2020, 24, 101243. [CrossRef]

47. Politakos, N.; Kortaberria, G. Exploring the self-assembly capabilities of ABA-type SBS, SIS, and their analogous hydrogenated copolymers onto different nanostructures using atomic force microscopy. Materials 2018, 11, 1529. [CrossRef]

48. Goswami, M.; Sumpter, B.G.; Huang, T.; Messman, J.M.; Gido, S.P.; Isaacs-Sodeye, A.I.; Mays, J.W. Tunable morphologies from charged block copolymers. Soft Matter 2010, 6, 6146-6154. [CrossRef]

49. Apolinar, Y.; Ramos, L.F.; Saade, H.; Díaz De Leon, R.; López, R.G. Polyisoprene nanoparticles prepared by polymerization in microemulsion. J. Nanomater. 2010, 2010, 1-6. [CrossRef]

50. Lee, K.M.; Han, C.D. Order-disorder transition induced by the hydroxylation of homogeneous polystyrene-block-polyisoprene copolymer. Macromolecules 2002, 35, 760-769. [CrossRef]

51. Wang, Q.; Yao, Q.; Chang, J.; Chen, L. Enhanced thermoelectric properties of CNT/PANI composite nanofibers by highly orienting the arrangement of polymer chains. J. Mater. Chem. 2012, 22, 17612-17618. [CrossRef]

52. Kobayashi, S.; Kataoka, H.; Ishizone, T.; Kato, T.; Ono, T.; Kobukata, S.; Ogi, H. Synthesis and properties of new thermoplastic elastomers containing poly[4-(1-adamantyl)styrene] hard segments. Macromolecules 2008, 41, 5502-5508. [CrossRef]

53. Kakiage, M.; Sekiya, M.; Yamanobe, T.; Uehara, H. Structural change with blending of crystalline/amorphous block copolymers having different types of microphase separations. Polymer 2011, 52, 6146-6153. [CrossRef]

54. Khandpur, A.K.; Förster, S.; Bates, F.S.; Hamley, I.W.; Ryan, A.J.; Bras, W.; Almdal, K.; Mortensen, K. Polyisoprene-Polystyrene Diblock Copolymer Phase Diagram near the Order-Disorder Transition. Macromolecules 1995, 28, 8796-8806. [CrossRef]

55. Miller-Chou, B.A.; Koenig, J.L. A review of polymer dissolution. Prog. Polym. Sci. 2003, 28, 1223-1270. [CrossRef]

56. Lindvig, T.; Michelsen, M.L.; Kontogeorgis, G.M. A Flory-Huggins model based on the Hansen solubility parameters. Fluid Phase Equilib. 2002, 203, 247-260. [CrossRef]

57. van Krevelen, D.W.; te Nijenhuis, K. Properties of Polymers: Their Correlation with Chemical Structure; Their Numerical Estimation and Prediction from Additive Group Contribution, 4th ed.; Elsevier: Amsterdam, The Netherlands, 2009; pp. 201-257.

58. Stühn, B. The relation between the microphase separation transition and the glass transition in diblock copolymers. J. Polym. Sci. Part B Polym. Phys. 1992, 30, 1013-1019. [CrossRef] 
59. Ren, Y.; Lodge, T.P.; Hillmyer, M.A. Synthesis, characterization, and interaction strengths of difluorocarbene-modified polystyrenepolyisoprene block copolymers. Macromolecules 2000, 33, 866-876. [CrossRef]

60. Davidock, D.A.; Hillmyer, M.A.; Lodge, T.P. Persistence of the gyroid morphology at strong segregation in diblock copolymers. Macromolecules 2003, 36, 4682-4685. [CrossRef]

61. Lai, C.; Russel, W.B.; Register, R.A.; Marchand, G.R.; Adamson, D.H. Phase behavior of styrene-isoprene diblock derivatives with varying conformational asymmetry. Macromolecules 2000, 33, 3461-3466. [CrossRef] 